\title{
Modern Sedentary Behaviors Favor Energy Consumption in Children and Adolescents
}

\author{
David Thivel • Mark S. Tremblay • Jean-Philippe Chaput
}

Published online: 13 October 2012

(C) Springer Science+Business Media New York 2012

\begin{abstract}
With the modernization of societies, daily living, school, chores and work tasks are less energy demanding and sedentary behaviors such as television viewing and video game playing are pervasive, particularly in children and adolescents. This sedentary behavior constellation has contributed to the progression of overweight and obesity. The low energy expenditure associated to daily sedentary behaviors has been postulated as the primary mechanism to explain population weight gain; however, recent evidence reveals that many sedentary behaviors also promote overconsumption of food. The present paper summarizes the available literature about the impact of sedentary behaviors on energy intake and appetite sensations in children and adolescents. Overall, screen-based sedentary behaviors (e.g., television viewing and video game playing) stimulate food intake in children and youth, while the influence of non-screen sedentary behaviors on feeding behavior remains largely unexplored. As in adults, insufficient sleep and waked resting positions (sitting or bed rest) are associated with increased energy consumption. Because all of these activities increase energy intake in the absence of hunger, the hedonic (rewarding) component of eating behavior seems to play an important role. At present, public health recommendations focus on increasing physical activity energy expenditure and reducing sedentary time in
\end{abstract}

\footnotetext{
D. Thivel $(\bowtie) \cdot$ M. S. Tremblay $\cdot$ J.-P. Chaput

Healthy Active Living and Obesity Research Group,

Children's Hospital of Eastern Ontario Research Institute,

401 Smyth Road,

Ottawa, Ontario, Canada K1H 8L1

e-mail: dthivel@cheo.on.ca

M. S. Tremblay $\cdot$ J.-P. Chaput

School of Human Kinetics, Faculty of Health Sciences,

University of Ottawa,

Ottawa, Ontario, Canada

children and youth. From an energy balance standpoint, the impact of modern sedentary behaviors on food consumption should also be considered if we want to curb childhood obesity. A better understanding of the physiological, psychological and sociological mechanisms involved in the nutritional adaptations to sedentary activities is needed to more adequately elucidate the interplay between sedentary behaviors, feeding behaviors and obesity.

Keywords Sedentary behaviors · Sleep · Energy intake · Energy expenditure $\cdot$ Children $\cdot$ Obesity $\cdot$ Energy consumption

\section{Introduction}

Years ago, human beings had to engage in vigorous physical activities to access food and ensure their subsistence. However, the recent modernization of our societies has resulted in convenient, palatable food availability that promotes the overconsumption of energy dense food, while requiring a decrease in daily physical activity energy expenditure. Although several putative etiological factors (such as genetics, epigenetic, hormonal disruption, family constraints, among others) have been identified and described for their implication in the obesity progression [1], behavioral changes are creating a sustained positive energy gap over time and are believed to be the main explanation for the growing prevalence of overweight and obesity in adults, children and adolescents. The decreased energy expenditure induced by this modern lifestyle does not only result from a decrease in physical activity but also relates to the omnipresence of sedentariness.

Traditionally, the management of energy balance has been achieved through an increase in physical activities to enhance energy expenditure, most of the time accompanied by dietary restriction to decrease energy intakes. However, it 
has been suggested that daily activities may not only affect individuals' energy expenditure but may also play a role in the control of appetite and energy intake. Recent evidence has shown that physical activity [2-4], sedentary behaviors and sleeping duration $[5 \bullet, 6 \bullet$ can also affect energy consumption at all ages. Such adaptations to modern daily activities may be of particular interest to better understand the progression of overweight and obesity but also to elaborate new weight loss strategies.

The relationship between daily activities and energy intake has been well documented in adults but remains poorly documented in children and adolescents. The objective of this brief review was to summarize the available literature regarding the impact of modern lifestyles, including increased sedentary behaviors (television viewing, video games, sitting and bed rest) and insufficient sleep, on energy intake and appetite control in children and adolescents.

\section{Influence of Specific Sedentary Activities on Feeding Behavior}

\section{Television (TV) Viewing}

TV viewing is currently one of the main sedentary pastimes at all ages and many publications have underlined its association with overweight and obesity [7]. Although this association has been attributed to the low energy expenditure it requires, it has been reported that watching TV is also associated with increased meal frequency and food consumption [8-14] regardless of appetite sensations $[15,16]$. Children and adolescents have been shown to consume a substantial proportion of their daily energy while watching TV, approximately $25 \%$ during weekend days and $20 \%$ during week days $[9,17,18]$, which could explain the differences in obesity-related measures found compared to children that do not eat in front of a TV [19].

Eating while watching TV does not only affect food intake quantitatively but also qualitatively. Red meat, pizza, snack food, soda and other energy-dense and palatable food items are mainly consumed while fruits and vegetables are neglected [11, 13, 20-23]. Attentional allocation to the TV stimulus has been put forward to explain such behaviors $[10,15]$. Habituation to food cues is a well established phenomenon [24-30] and is controlled by integrated signals from sensory, neuronal and digestive systems [31-33]. This habituation can be affected by providing food [31,33] and non-food [34] stimuli requiring attention from the habituating stimuli [16]. TV viewing disrupts habituation to those food cues and leads to increased food intake in children [16]. There is evidence that TV acts as a distracter in children, delaying satiation and reducing satiety signals from previously ingested food $[15,35,36]$. It is thought that TV watching limits the capacity of an individual to monitor satiety signals and then leads to increased caloric intake $[35,37]$. As the low energy expenditure-induced by watching TV is associated with body weight, it seems clear that eating while watching TV is also involved. It remains unexplored whether or not watching TV may affect subsequent energy intake. In free-living conditions, many children and adolescents watch TV before taking their meals with their family and no work has been conducted so far to know whether or not children's food consumption during this following meal is affected.

To date, we are aware of only one study that experimentally measured energy intake at a buffet meal after a 45 minute TV viewing session in pre-pubertal children [38•]. The authors observed a significantly higher energy intake in overweight kids $(806 \pm 51 \mathrm{kcal})$ compared to lean ones $(605$ $\pm 65 \mathrm{kcal}$ ) after TV watching (Fig. 1). According to their results, watching TV for 45 minutes was associated with a higher subsequent energy intake in lean children than 45 minutes of resistance or swimming exercises, while their overweight counterparts ate more after exercise sessions compared with TV [38•]. Cognitive working [39, 40] and video game playing [41•] have been shown to increase subsequent food consumption, but data are lacking for TV watching (Table 1).

\section{Video Game Playing}

Although watching TV remains the preferred leisure time activity of most children and adolescents, the interest in and practice of video games have been growing for the last years in youth [42] and more than $50 \%$ of children report eating while playing computer or video games [43]. Most American 12 to 17 years old report playing with electronic devices (internet, computer, console or mobile games); $31 \%$ every day and approximately $20 \% 3-5$ days a week [44]. This contemporary trend has been related to the progression of overweight and obesity [45-48] and has been attributed primarily to decreased energy expenditure [49]. However, since the practice of computer-related activities promotes overconsumption of food in adults [39, 40] it may be reasonable to speculate that a similar relationship exists with video game playing in children. Very few data are actually available concerning the relationship between seated video game playing and incidental energy consumption, particularly in children and youth (Table 1).

A recent randomized, cross-over study showed that a 1hour seated video game session was accompanied by an increase in energy consumption $(+80 \mathrm{kcal})$ compared with a control, relaxing session in healthy adolescents [41•]. This overconsumption of food after playing seated video games was not accompanied by increased subjective appetite sensations (assessed by visual analogue scales) nor by increases 


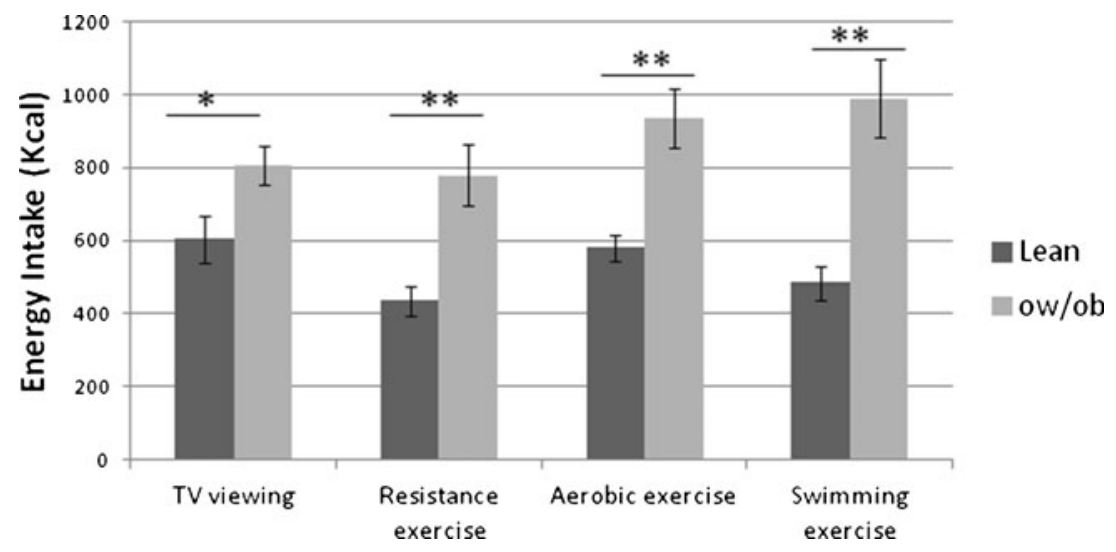

Fig. 1 Ad libitum energy intake (in kcal) following a 45 minute TV viewing session in lean and obese prepubertal children compared to 45 minute physical activity sessions $(* \mathrm{p}<0.05 ; * * \mathrm{p}<0.01)$. Overweight and obese $(\mathrm{OW} / \mathrm{OB})$ children showed a higher consumption after swimming compared to TV viewing $(\mathrm{p}<0.05)$. The lean children

in objective markers of appetite (i.e., appetite-related hormones). The mental stress induced by the video game practice has been proposed by the authors to explain this increased food intake. The video game session induced a $25 \mathrm{kcal}$ increased energy expenditure above the control session, which remains low and thus very unlikely to explain this higher food ingestion.

If seated video game playing provokes a positive energy gap, it raises questions regarding the potential impact of active video games (involving large body movements) on total energy balance and consequently its potential in preventing/managing obesity. Mathieu and Kakinami suggested that for an identical mental stress induced by active video games compared to sedentary games, excess energy intake could be offset by the increased energy expenditure from active video games, producing a negative energy balance [50]. In 2008, Graves and collaborators found a $51 \%$ higher energy expenditure (which corresponded to $2.86 \mathrm{kcal}$ per min) during active Wii video games (15 minutes) compared to sedentary ones in lean 13 to 15 years old youth [51]. Such increased energy expenditure during active video games is also in agreement with recent systematic reviews examining the acute effects of active gaming on energy showed a lower energy intake after the resistance session compared to the TV one $(p<0.05)$. (Adapted from: Nemet D, Arieli R, Meckel Y, Eliakim A. Immediate post-exercise energy intake and macronutrient preferences in normal weight and overweight pre-pubertal children. Int J Pediatr Obes. 2010;5(3):221-9) [38•]

expenditure in children and youth $[52,53]$. Some studies have compared adolescents' energy expenditure while watching TV seated, playing seated video games, playing active video games or watching TV while walking on a treadmill. The energy expenditure of active gaming has been found to be 2 to 3 times the energy expended during seated television viewing [54]. Lanningham-Foster and collaborators showed that watching TV seated or playing sedentary video games increased energy expenditure by $20 \%$ and $22 \%$, respectively, compared to resting energy expenditure in 8 to 12 years old children [55]. In the same paper, the authors also underlined that walking at $1.5 \mathrm{mile} / \mathrm{h}$ while watching TV led to a $138 \pm 40 \%$ increase in energy expenditure compared to resting energy expenditure and that playing the "Dance Dance Revolution" game (Konami Digital Entertainment) produced an increased energy expenditure of $172 \pm 68 \%$ above resting energy expenditure [55]. However, those are acute experiments, while Chaput and Sjödin pointed out that increases in energy expenditure from active video games are unlikely to produce any weight loss due to possible compensations in food intake and/or compensatory activity adjustments [56]. In support of this hypothesis, it has recently been shown that body weight
Table 1 Energy intake subsequent to sedentary and imposed sedentary behaviors in lean and overweight/obese children and adolescents

$<$ : EI after activity inferior to;

$>$ : EI after activity superior to;

$=$ : EI unchanged.

EI: energy intake; TV: television; VG: video games.

\begin{tabular}{lllll}
\hline Authors & Weight status & Activity & Duration (min) & EI modification \\
\hline Chaput et al. 2011 [41•] & lean & Sitting & 60 & $<$ Passive VG \\
Thivel et al. 2012 [91] & obese & Bed rest & 210 & $>$ control session \\
Tamam et al. 2012 [92] & lean & Board games & 15 & $=$ exercise \\
Tamam et al. 2012 [92] & obese & Board games & 15 & $=$ exercise \\
Nemet et al. 2011 [38•] & lean & TV & 45 & $>$ exercise \\
Nemet et al. 2011 [38•] & overweight & TV & 45 & $<$ exercise \\
Mellecker et al. 2010 [59] & lean & Passive VG & 60 & $=$ Passive VG + walking \\
Chaput et al. 2011 [41•] & lean & Passive VG & 60 & $>$ sitting \\
\hline
\end{tabular}


of overweight and obese children did not change after a 6-month active video game intervention, suggesting some form of behavior compensation [57].

Recently, Lyons and collaborators compared the acute use of active versus passive video games in adults in terms of energy balance [58]. According to their results, active video games favored a lower energy surplus thanks to a slight decreased energy intake and a higher energy expenditure, but energy balance remained positive [58]. We were able to find only one study that compared sedentary and active video gaming in terms of energy consumption in youth [59]. In this study, a sedentary (seated) 1-hour video game session was not compared with an active video game per se, but the 27 participants aged $11 \pm 1.0$ years had to play the same game while walking on a treadmill at $1.2 \mathrm{~km} / \mathrm{h}$ for an hour. Using the exact same game in both conditions allowed the authors to match conditions on mental stress. No significant energy intake difference was found between the two sessions, suggesting that adding a motor component to video games does not affect the control of energy consumption in youth. Further studies are needed to better understand the respective roles of video game-induced mental stress and energy expenditure in control of energy intake and appetite in children and youth. Until such data are available, caution should be exercised with regard to prescribing active video games to prevent or manage childhood obesity due to possible energy balance compensatory behaviors.

\section{Insufficient Sleep and Imposed Sedentary Behavior}

Sleep curtailment has become endemic in modern societies, with population statistics revealing a decrease in sleep duration by more than 1 hour in children over the past few decades [60]. Sleep represents the most sedentary activity in humans, generating an energy cost of approximately $1 \mathrm{kcal} \cdot-$ $\min ^{-1}$ in normal weight adults [61] and $0.94 \mathrm{kcal} \cdot \mathrm{min}^{1}$ in youth [62]. An accumulating body of evidence shows an association between reduced sleep and the progression of overweight and obesity in youth [63-69]. In children, short sleeping hours have been shown to predict overweight and obesity to a greater extent than low physical activity level or TV viewing [70]. Some data also suggest that short sleep duration preferentially favors central adiposity rather than total adiposity [71, 72]. Decreased circulating levels of the appetite suppressing hormone leptin accompanied by an increase in the orexigenic hormone ghrelin have been advanced to explain such an impact of sleep restriction on energy intake and then weight gain [73-77]. Accordingly, both appetite and hunger scores are elevated by sleep deprivation and such increases were particularly noted for high fat and high carbohydrate foods in adults [77]. Recent data, however, showed that short-term sleep restriction (three consecutive nights of 4 hours in bed) was accompanied by a decreased motivation to eat in adolescents boys [78].

Some interventional work also failed to replicate these alterations in the appetite-regulating hormones as a response to sleep restriction [79-81]. According to these studies, the increased energy consumption observed in short-duration sleepers results from behavioral trends and a higher time available to consume food [79-81]. Nedeltcheva and collaborators reported an increased intake of calories from snacks without leptin or ghrelin modifications after a bed time restriction in free living conditions [79]. These results support the theory of a non-homeostatic adaptation of food intake with sleep restriction in adults. Similar results have been shown in adolescents with a two-fold increased risk of consuming a high level of energy from snacks in shortduration sleepers [82]. As part of the HELENA study, Garaulet and collaborators recently found increased overall food intake among European adolescents with shorter sleep duration, while those who sleep longer presented better eating habits (Fig. 2) [83•]. In 2009, Westerlund et al. investigated this association between sleep duration and eating pattern in more than 1000 children aged 10-11 years [84]. According to their results, short sleep duration was associated with more frequent consumption of energy dense foods such as fast foods and sweets, and a lower intake of nutrient-rich items such as fruits and vegetables. This association was greater among boys compared to girls, and during school days compared to weekend days [84]. Similar to adults $[5 \bullet, 6 \bullet]$, insufficient or low-quality sleep also affects children and adolescents' energy balance through its impact on both energy expenditure and energy intake. However, increased food intake associated with short sleep duration (via an up-regulation of appetite-stimulating hormones and/or a longer exposure to an obesogenic environment) seems to be the main explanation for shortened sleep as a new determinant of obesity $[69,85,86]$.

Some activities or waked rest positions such as sitting or bed rest have been classified as "physical inactivities" [87] though there appears to be converging agreement that they should be referred to as sedentary behaviors [87]. Such activities have been pointed out for their implication in the progression of overweight and obesity through the very low energy expenditure they generate. In 2011, Santiago and collaborators have shown that those imposed sedentary behaviors are important in 6-12 years old children, especially during weekends, and associated with a lack of fruits and vegetables consumption (recommendation not reached) [88]. An acute session of sitting has been recently shown to decrease daily energy expenditure without any appetite reduction, which would favor a positive caloric balance and possibly weight gain [89]. However, Bergougnian and collaborators have questioned the impact of two weeks of bed rest induced physical inactivity on spontaneous energy 
Fig. 2 Percentage of European adolescents achieving food intake recommendations by sleep time $(<8 \mathrm{~h}$ or $>8 \mathrm{~h})$ $(* * \mathrm{p}<0.01 ; * * * \mathrm{p}<0.001)$. (Adapted from: Garaulet M, Ortega FB, Ruiz JR, Rey-Lopez JP, Beghin L, Manios Y et al. Short sleep duration is associated with increased obesity markers in European adolescents: effect of physical activity and dietary habits. The HELENA study. Int J Obes (Lond). 2012;35(10):1308-17) [83•]

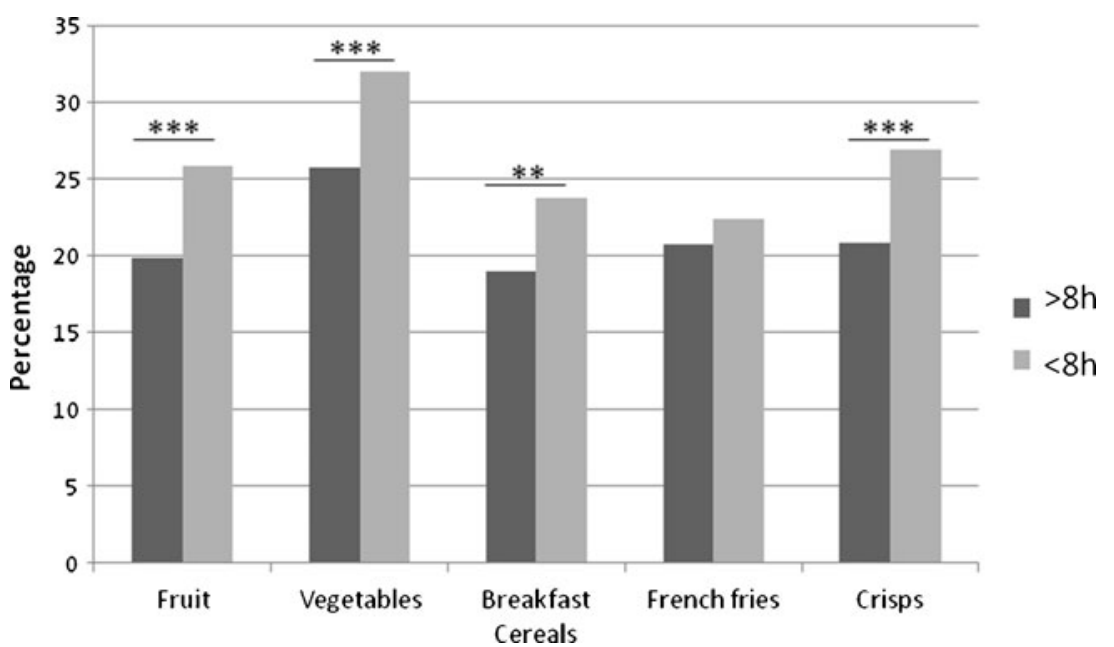

intake, and showed that in lean adults spontaneous energy intake tends to decrease to match for decreased energy expenditure, preserving energy balance [90]. We could find no experimental study that examined the effects of imposed sedentary behavior on energy intake in children or youth. Preliminary data indicate that an acute session of bed rest (approximately 3 hours) induces an important increase in energy intake in obese adolescents at dinner time (the 3-hour bed rest was completed during the morning) compared to a control session $(819 \pm 123$ and $667 \pm 152 \mathrm{kcal}$, respectively) [91]. As previously mentioned with video game playing, this impact on energy intake is not accompanied by any changes in appetite sensations. It should be noted that in this last study, the adolescents mainly watched television, played video games or did their homework during the control session, which could suggest a greater impact of these specific behaviors on energy intake, as previously reported [41•]. However, in their work, Chaput and collaborators used a one-hour sitting session as a control condition compared with a one hour video game and found a lower energy intake after sitting (just relaxing comfortably on a chair) in lean adolescents [41•]. Such discrepancies also raise the question of the duration of the activity. Clearly, further studies are needed in this area.

\section{Other Sedentary Behaviors}

During the day, children and adolescents are also confronted to other kinds of sedentary behaviors, defined as non-screen sedentary behaviors and their potential impact on energy intake has to be considered. Tamam and collaborators have for instance recently reported that 15 minutes of board games and intensive exercise similarly affect energy intake in obese and lean adolescents [92]. Although homework has been shown to be the most prevalent after school behavior (with screen time) in youth [93, 94], no data are currently available relating the time spent completing homework and energy intake. Such a cognitive task has been shown to slightly increase energy consumption in university students $[39,40]$ but this issue remains unstudied in children and adolescents. Likewise, the influence of reading or listening to music on appetite control is an area largely unexplored in children. Using motorized transportation to go to school also represents a sedentary behavior compared to active transportation, and has been associated to overweight and obesity prevalence in children and youth [95]. This association has been mainly explained through the lower energy expenditure required using such a transportation but further studies may be of particular interest to question whether or not it also represents an opportunity for food intake and particularly takeaway or fast food (also knowing that screen time is now common in automobiles). Recent studies effectively underlined that adolescents that are used to consuming fast-food outlets tend to consume more unhealthy foods and were likely to have higher weight status [96]. This has also been pointed out in children where the frequency of fast food consumption has been inversely related with body mass index [97]. As recently suggested by the Active Healthy Kids Canada 2012 Report Card [98], more research is required regarding the implication of non-screen sedentary behaviors in the progression of obesity.

\section{Conclusions}

The last two decades have been particularly marked by a shift to sedentary, indoor activities in children and adolescents while outdoor and active play has declined [98]. Electronic media devices are now commonplace in everyday life and children and youth are experiencing shorter sleep durations [98]. Sleep reduction and sedentary activities have been clearly identified as culprits in the progression of overweight and obesity among children and youth. This paper highlights that such behaviors do not only 
produce low energy expenditure but also promote overconsumption of food in children and adolescents. This increased energy intake associated with sedentary behaviors and/or insufficient sleep does not appear to be associated with hunger sensations, implicating the hedonic and rewarding aspects of feeding behaviors. Further studies are now needed to delineate whether such nutritional adaptations to modern sedentary activities are similar between lean and overweight or obese children and youth, and their implications for future recommendations and weight loss strategies.

Acknowledgments Jean-Philippe Chaput holds a Junior Research Chair in Healthy Active Living and Obesity Research.

Disclosure Conflicts of interest: D. Thivel: none; M.S. Tremblay: is employed by the Children's Hospital of Eastern Ontario Research Institute as the Director of Healthy Active Living and Obesity Research; he sits on the Active Healthy Kids Canada Board and on many national and international committees for different not-for-profit organizations (ParticipACTION, Canadian Society for Exercise Physiology, ...); his expenses for attending meetings are reimbursed; also he has given about 100 invited presentations at conferences, universities, public health institutes, etc., wherein his expenses are reimbursed and sometimes he receives a speaker honorarium. J.-P Chaput: none.

\section{References}

Papers of particular interest, published recently, have been highlighted as:

- Of importance

1. McAllister EJ, Dhurandhar NV, Keith SW, Aronne LJ, Barger J, Baskin M, et al. Ten putative contributors to the obesity epidemic. Crit Rev Food Sci Nutr. 2009;49(10):868-913.

2. Blundell JE, Stubbs RJ, Hughes DA, Whybrow S, King NA. Cross talk between physical activity and appetite control: does physical activity stimulate appetite? Proc Nutr Soc. 2003;62(3):651-61.

3. Martins C, Morgan L, Truby H. A review of the effects of exercise on appetite regulation: an obesity perspective. Int J Obes (Lond). 2008;32(9):1337-47.

4. Thivel D, Blundell JE, Duche P, Morio B. Acute exercise and subsequent nutritional adaptations: what about obese youths? Sports Med. 2012;42(7):607-13.

5. - Chaput JP, Klingenberg L, Astrup A, Sjodin AM. Modern sedentary activities promote overconsumption of food in our current obesogenic environment. Obes Rev. 2011;12(5):e12-20. The paper reviews the recent literature regarding the impact of sedentary behaviors on energy intake, underlying their implication in individuals' overconsumption.

6. - Chaput JP, Klingenberg L, Sjodin A. Do all sedentary activities lead to weight gain: sleep does not. Curr Opin Clin Nutr Metab Care. 2010;13(6):601-7. The paper points out the implication of sedentary behaviors in weight gain and emphasizes that insufficient sleep is an important contributor to weight gain.

7. Swinburn B, Shelly A. Effects of TV time and other sedentary pursuits. Int J Obes (Lond). 2008;32 Suppl 7:S132-6.

8. Sonneville KR, Gortmaker SL. Total energy intake, adolescent discretionary behaviors and the energy gap. Int J Obes (Lond). 2008;32 Suppl 6:S19-27.
9. Matheson DM, Killen JD, Wang Y, Varady A, Robinson TN. Children's food consumption during television viewing. Am J Clin Nutr. 2004;79(6):1088-94.

10. Stroebele N, de Castro JM. Television viewing is associated with an increase in meal frequency in humans. Appetite. 2004;42 (1):111-3.

11. Coon KA, Goldberg J, Rogers BL, Tucker KL. Relationships between use of television during meals and children's food consumption patterns. Pediatrics. 2001;107(1):E7.

12. Crespo CJ, Smit E, Troiano RP, Bartlett SJ, Macera CA, Andersen RE. Television watching, energy intake, and obesity in US children: results from the third National Health and Nutrition Examination Survey, 1988-1994. Arch Pediatr Adolesc Med. 2001;155(3):360-5.

13. French SA, Story M, Neumark-Sztainer D, Fulkerson JA, Hannan P. Fast food restaurant use among adolescents: associations with nutrient intake, food choices and behavioral and psychosocial variables. Int J Obes Relat Metab Disord. 2001;25(12):1823-33.

14. McNutt SW, Hu Y, Schreiber GB, Crawford PB, Obarzanek E, Mellin L. A longitudinal study of the dietary practices of black and white girls 9 and 10 years old at enrollment: the NHLBI Growth and Health Study. J Adolesc Health. 1997;20(1):27-37.

15. Bellisle F, Dalix AM, Slama G. Non food-related environmental stimuli induce increased meal intake in healthy women: comparison of television viewing versus listening to a recorded story in laboratory settings. Appetite. 2004;43(2):175-80.

16. Temple JL, Giacomelli AM, Kent KM, Roemmich JN, Epstein LH. Television watching increases motivated responding for food and energy intake in children. Am J Clin Nutr. 2007;85(2):355-61.

17. Gore SA, Foster JA, DiLillo VG, Kirk K, Smith West D. Television viewing and snacking. Eat Behav. 2003;4(4):399-405.

18. Van den Bulck J, Van Mierlo J. Energy intake associated with television viewing in adolescents, a cross sectional study. Appetite. 2004;43(2):181-4.

19. Isacco L, Lazaar N, Ratel S, Thivel D, Aucouturier J, Dore E, et al. The impact of eating habits on anthropometric characteristics in French primary school children. Child Care Health Dev. 2010;36 (6):835-42.

20. Blass EM, Anderson DR, Kirkorian HL, Pempek TA, Price I, Koleini MF. On the road to obesity: television viewing increases intake of high-density foods. Physiol Behav. 2006;88(4-5):597-604.

21. Francis LA, Lee Y, Birch LL. Parental weight status and girls' television viewing, snacking, and body mass indexes. Obes Res. 2003;11(1):143-51.

22. Vader AM, Walters ST, Harris TR, Hoelscher DM. Television viewing and snacking behaviors of fourth- and eighth-grade schoolchildren in Texas. Prev Chron Dis. 2009;6(3):A89.

23. Rey-Lopez JP, Ruiz JR, Ortega FB, Verloigne M, VicenteRodriguez G, Gracia-Marco L, et al. Reliability and validity of a screen time-based sedentary behaviour questionnaire for adolescents: the HELENA study. Eur J Public Health. 2012;22(3):373-7.

24. Swithers SE, Martinson FA. Habituation of oral responding in adult rats. Behav Neurosci. 1998;112(1):213-24.

25. Swithers SE, Westneat MW, Hall WG. Electromyographic analysis of oral habituation in rat pups. Physiol Behav. 1998;63(2):197-203.

26. Critchley HD, Rolls ET. Hunger and satiety modify the responses of olfactory and visual neurons in the primate orbitofrontal cortex. J Neurophysiol. 1996;75(4):1673-86.

27. Epstein LH, Caggiula AR, Rodefer JS, Wisniewski L, Mitchell SL. The effects of calories and taste on habituation of the human salivary response. Addict Behav. 1993;18(2):179-85.

28. Epstein LH, Mitchell SL, Caggiula AR. The effect of subjective and physiological arousal on dishabituation of salivation. Physiol Behav. 1993;53(3):593-7.

29. Epstein LH, Paluch R, Smith JD, Sayette M. Allocation of attentional resources during habituation to food cues. Psychophysiology. 1997;34(1):59-64. 
30. Epstein LH, Paluch RA. Habituation of facial muscle responses to repeated food stimuli. Appetite. 1997;29(2):213-24.

31. Epstein LH, Saad FG, Handley EA, Roemmich JN, Hawk LW, McSweeney FK. Habituation of salivation and motivated responding for food in children. Appetite. 2003;41(3):283-9.

32. Swithers SE, Hall WG. Does oral experience terminate ingestion? Appetite. 1994;23(2):113-38.

33. Temple JL, Kent KM, Giacomelli AM, Paluch RA, Roemmich JN, Epstein LH. Habituation and recovery of salivation and motivated responding for food in children. Appetite. 2006;46(3):280-4.

34. Epstein LH, Saad FG, Giacomelli AM, Roemmich JN. Effects of allocation of attention on habituation to olfactory and visual food stimuli in children. Physiol Behav. 2005;84(2):313-9.

35. Bellissimo N, Pencharz PB, Thomas SG, Anderson GH. Effect of television viewing at mealtime on food intake after a glucose preload in boys. Pediatr Res. 2007;61(6):745-9.

36. Francis LA, Birch LL. Does eating during television viewing affect preschool children's intake? J Am Diet Assoc. 2006;106(4):598-600.

37. Brunstrom JM, Mitchell GL. Effects of distraction on the development of satiety. Br J Nutr. 2006;96(4):761-9.

38. - Nemet D, Arieli R, Meckel Y, Eliakim A. Immediate post-exercise energy intake and macronutrient preferences in normal weight and overweight pre-pubertal children. Int J Pediatr Obes. 2010;5(3):2219. The paper shows an important energy consumption after 45 minutes of TV viewing in lean and obese pre-pubertal children.

39. Chaput JP, Drapeau V, Poirier P, Teasdale N, Tremblay A. Glycemic instability and spontaneous energy intake: association with knowledge-based work. Psychosom Med. 2008;70(7):797-804.

40. Chaput JP, Tremblay A. Acute effects of knowledge-based work on feeding behavior and energy intake. Physiol Behav. 2007;90 (1):66-72.

41. - Chaput JP, Visby T, Nyby S, Klingenberg L, Gregersen NT, Tremblay A, et al. Video game playing increases food intake in adolescents: a randomized crossover study. Am J Clin Nutr. 2011;93(6):1196-203. In this work, a one hour video game session is shown to increase energy intake in adolescents.

42. Christakis DA, Ebel BE, Rivara FP, Zimmerman FJ. Television, video, and computer game usage in children under 11 years of age. J Pediatr. 2004;145(5):652-6.

43. Moag-Stahlberg A, Miles A, Marcello M. What kids say they do and what parents think kids are doing: the ADAF/Knowledge Networks 2003 Family Nutrition and Physical Activity Study. J Am Diet Assoc. 2003;103(11):1541-6.

44. Lenhart A, Kahne J, Middaugh E, Macgill AR, Evans C, Vitak J. Teens, video games, and civics. Pew internet \& American Life Project, 16 September 2008. . 2008. http://www.pewinternet.org/Reports/2008/ Teens-Video-Games-and-civics.aspx. Accessed March 20112008.

45. Ray M, Jat KR. Effect of electronic media on children. Indian Pediatr. 2010;47(7):561-8.

46. Schneider M, Dunton GF, Cooper DM. Media use and obesity in adolescent females. Obesity (Silver Spring). 2007;15(9):2328-35.

47. Carvalhal MM, Padez MC, Moreira PA, Rosado VM. Overweight and obesity related to activities in Portuguese children, 7-9 years. Eur J Public Health. 2007;17(1):42-6.

48. Stettler N, Signer TM, Suter PM. Electronic games and environmental factors associated with childhood obesity in Switzerland. Obes Res. 2004;12(6):896-903.

49. Janz KF, Mahoney LT. Maturation, gender, and video game playing are related to physical activity intensity in adolescents: the Muscation Study. Pediatr Exerc Sci. 1997;9:353-63.

50. Mathieu ME, Kakinami L. Active video games could be the solution to the increased energy intake reported with sedentary video games. Am J Clin Nutr. 2011;94:1150-6.

51. Graves L, Stratton G, Ridgers ND, Cable NT. Energy expenditure in adolescents playing new generation computer games. $\mathrm{Br} \mathrm{J}$ Sports Med. 2008;42(7):592-4.
52. Peng W, Lin JH, Crouse J. Is playing exergames really exercising? A meta-analysis of energy expenditure in active video games. Cyberpsychol Behav Soc Netw. 2011;14(11):681-8.

53. Barnett A, Cerin E, Baranowski T. Active video games for youth: a systematic review. J Phys Act Health. 2011;8(5):724-37.

54. Graf DL, Pratt LV, Hester CN, Short KR. Playing active video games increases energy expenditure in children. Pediatrics. 2009;124(2):534-40.

55. Lanningham-Foster L, Foster RC, McCrady SK, Jensen TB, Mitre $\mathrm{N}$, Levine JA. Activity-promoting video games and increased energy expenditure. J Pediatr. 2009;154(6):819-23.

56. Chaput JP, Sjodin AM. Active video games could be the solution to the increased energy intake reported with sedentary video games: reply to M-E Mathieu and L Kakinami. Am J Clin Nutr. 2011;94:1150-6.

57. Maddison R, Foley L, Ni Mhurchu C, Jiang Y, Jull A, Prapavessis $\mathrm{H}$. Effects of active video games on body composition: a randomized controlled trial. Am J Clin Nutr. 2011;94(1):156-63.

58. Lyons EJ, Tate DF, Ward DS, Wang X. Energy intake and expenditure during sedentary screen time and motion-controlled video gaming. Am J Clin Nutr. 2012;96(2):234-9.

59. Mellecker RR, Lanningham-Foster L, Levine JA, McManus AM. Energy intake during activity enhanced video game play. Appetite. 2010;55(2):343-7.

60. Matricciani L, Olds T, Petkov J. In search of lost sleep: secular trends in the sleep time of school-aged children and adolescents. Sleep Med Rev. 2011;16(3):203-11.

61. Tremblay MS, Esliger DW, Tremblay A, Colley R. Incidental movement, lifestyle-embedded activity and sleep: new frontiers in physical activity assessment. Can J Public Health. 2007;98 Suppl 2:S208-17.

62. Zakeri IF, Adolph AL, Puyau MR, Vohra FA, Butte NF. Multivariate adaptive regression splines models for the prediction of energy expenditure in children and adolescents. J Appl Physiol. 2010;108 (1):128-36

63. Locard E, Mamelle N, Billette A, Miginiac M, Munoz F, Rey S. Risk factors of obesity in a five year old population. Parental versus environmental factors. Int J Obes Relat Metab Disord. 1992;16(10):721-9.

64. Sekine M, Yamagami T, Handa K, Saito T, Nanri S, Kawaminami $\mathrm{K}$, et al. A dose-response relationship between short sleeping hours and childhood obesity: results of the Toyama Birth Cohort Study. Child Care Health Dev. 2002;28(2):163-70.

65. Padez C, Mourao I, Moreira P, Rosado V. Prevalence and risk factors for overweight and obesity in Portuguese children. Acta Paediatr. 2005;94(11):1550-7.

66. Cappuccio FP, Taggart FM, Kandala NB, Currie A, Peile E, Stranges $\mathrm{S}$, et al. Meta-analysis of short sleep duration and obesity in children and adults. Sleep. 2008;31(5):619-26.

67. Hitze B, Bosy-Westphal A, Bielfeldt F, Settler U, PlachtaDanielzik S, Pfeuffer M, et al. Determinants and impact of sleep duration in children and adolescents: data of the Kiel Obesity Prevention Study. Eur J Clin Nutr. 2009;63(6):739-46.

68. Seicean A, Redline S, Seicean S, Kirchner HL, Gao Y, Sekine M, et al. Association between short sleeping hours and overweight in adolescents: results from a US Suburban High School survey. Sleep Breath. 2007;11(4):285-93.

69. Klingenberg L, Sjodin A, Holmback U, Astrup A, Chaput JP. Short sleep duration and its association with energy metabolism. Obes Rev. 2012;13(7):565-77.

70. Chaput JP, Brunet M, Tremblay A. Relationship between short sleeping hours and childhood overweight/obesity: results from the 'Quebec en Forme' Project. Int J Obes (Lond). 2006;30 (7): $1080-5$.

71. Chaput JP, Tremblay A. Does short sleep duration favor abdominal adiposity in children? Int J Pediatr Obes. 2007;2(3):188-91. 
72. Chaput JP, Despres JP, Bouchard C, Tremblay A. Short sleep duration preferentially increases abdominal adiposity in adults: preliminary evidence. Clin Obes. 2011;1:141-6.

73. Spiegel K, Leproult R, L'Hermite-Baleriaux M, Copinschi G, Penev PD, Van Cauter E. Leptin levels are dependent on sleep duration: relationships with sympathovagal balance, carbohydrate regulation, cortisol, and thyrotropin. J Clin Endocrinol Metab. 2004;89(11):5762-71.

74. Taheri S, Lin L, Austin D, Young T, Mignot E. Short sleep duration is associated with reduced leptin, elevated ghrelin, and increased body mass index. PLoS Med. 2004;1(3):e62.

75. Chaput JP, Despres JP, Bouchard C, Tremblay A. Short sleep duration is associated with reduced leptin levels and increased adiposity: results from the Quebec family study. Obesity (Silver Spring). 2007;15(1):253-61.

76. Schuessler P, Uhr M, Ising M, Schmid D, Weikel J, Steiger A. Nocturnal ghrelin levels-relationship to sleep EEG, the levels of growth hormone, ACTH and cortisol-and gender differences. J Sleep Res. 2005;14(4):329-36.

77. Spiegel K, Tasali E, Penev P, Van Cauter E. Brief communication: Sleep curtailment in healthy young men is associated with decreased leptin levels, elevated ghrelin levels, and increased hunger and appetite. Ann Intern Med. 2004;141 (11):846-50.

78. Klingenberg L, Chaput JP, Holmback U, Jennum P, Astrup A, Sjodin A. Sleep restriction is not associated with a positive energy balance in adolescent boys. Am J Clin Nutr. 2012;96:240-8.

79. Nedeltcheva AV, Kilkus JM, Imperial J, Kasza K, Schoeller DA, Penev PD. Sleep curtailment is accompanied by increased intake of calories from snacks. Am J Clin Nutr. 2009;89(1):126-33.

80. Schmid SM, Hallschmid M, Jauch-Chara K, Wilms B, Benedict C, Lehnert $\mathrm{H}$, et al. Short-term sleep loss decreases physical activity under free-living conditions but does not increase food intake under time-deprived laboratory conditions in healthy men. Am J Clin Nutr. 2009;90(6):1476-82.

81. Bosy-Westphal A, Hinrichs S, Jauch-Chara K, Hitze B, Later W, Wilms B, et al. Influence of partial sleep deprivation on energy balance and insulin sensitivity in healthy women. Obes Facts. 2008;1(5):266-73.

82. Weiss A, Xu F, Storfer-Isser A, Thomas A, Ievers-Landis $\mathrm{CE}$, Redline $\mathrm{S}$. The association of sleep duration with adolescents' fat and carbohydrate consumption. Sleep. 2010;33 (9):1201-9.

83. - Garaulet M, Ortega FB, Ruiz JR, Rey-Lopez JP, Beghin L, Manios Y, et al. Short sleep duration is associated with increased obesity markers in European adolescents: effect of physical activity and dietary habits. The HELENA study. Int J Obes (Lond). 2012;35(10):1308-17. This paper illustrates the relationship between short sleep duration and healthy eating habits among European children and adolescents.
84. Westerlund L, Ray C, Roos E. Associations between sleeping habits and food consumption patterns among 10-11-year-old children in Finland. Br J Nutr. 2009;102(10):1531-7.

85. Chaput JP, Tremblay A. Insufficient Sleep as a Contributor to Weight Gain: An Update. Curr Obes Rep. 2012; doi:10.1007/ s13679-012-0026-7.

86. Chamorro RA, Duran SA, Reyes SC, Ponce R, Algarin CR, Peirano PD. Sleep deprivation as a risk factor for obesity. Rev Med Chil. 2011;139(7):932-40.

87. Thyfault JP, Booth FW. Lack of regular physical exercise or too much inactivity. Curr Opin Clin Nutr Metab Care. 2011;14(4):374-8.

88. Santiago S, Cuervo M, Zazpe I, Ortega A, Garcia-Perea A, Martinez JA. [Weight status, dietary habits and physical activity among 612 year-old children in Castile-La Mancha.]. Ann Pediatr (Barc). 2011. doi:10.1016/j.anpedi.2011.07.009.

89. Granados K, Stephens BR, Malin SK, Zderic TW, Hamilton MT, Braun B. Appetite regulation in response to sitting and energy imbalance. Appl Physiol Nutr Metab. 2012;37(2):323-33.

90. Bergouignan A, Rudwill F, Simon C, Blanc S. Physical inactivity as the culprit of metabolic inflexibility: evidences from bed-rest studies. J Appl Physiol. 2011;111(4):1201-10.

91. Thivel D, Metz L, Aucouturier J, Brakoniecki K, Morio B, Duché $\mathrm{P}$. Intensive exercise and physical inactivity have opposite effects on daily energy intake and energy balance in obese adolescents. Obes Facts. 2012(Suppl 1);5:273.

92. Tamam S, Bellissimo N, Patel BP, Thomas SG, Anderson GH. Overweight and obese boys reduce food intake in response to a glucose drink but fail to increase intake in response to exercise of short duration. Appl Physiol Nutr Metab. 2012;37(3):520-9.

93. Atkin AJ, Gorely T, Biddle SJ, Marshall SJ, Cameron N. Critical hours: physical activity and sedentary behavior of adolescents after school. Pediatr Exerc Sci. 2008;20(4):446-56.

94. Biddle SJ, Gorely T, Marshall SJ, Cameron N. The prevalence of sedentary behavior and physical activity in leisure time: a study of Scottish adolescents using ecological momentary assessment. Prev Med. 2009;48(2):151-5.

95. Andegiorgish AK, Wang J, Zhang X, Liu X, Zhu H. Prevalence of overweight, obesity, and associated risk factors among school children and adolescents in Tianjin, China. Eur J Pediatr. 2012;171(4):697-703.

96. Fraser LK, Edwards KL, Cade JE, Clarke GP. Fast food, other food choices and body mass index in teenagers in the United Kingdom (ALSPAC): a structural equation modelling approach. Int $\mathrm{J}$ Obes (Lond). 2011;35(10):1325-30.

97. Patterson R, Risby A, Chan MY. Consumption of takeaway and fast food in a deprived inner London Borough: are they associated with childhood obesity? BMJ Open. 2012;2(3). doi:10.1136/ bmjopen-2011-000402.

98. Active, healthy, Kids, Canada, Group. Is active play extinct? 2012 Active Healthy Kids canada Report card on Physical activity for children and youth. Toronto 2012 . 